\title{
Yemen Televizyon Kanallarının Ramazan Ayında İzlenme Oranlarının Artışı
}

\section{The Increase of Viewing Ratio of Yemeni Television Channels in Ramadan Month}

\author{
Saddam ALNADHEEF*
}

\begin{abstract}
$\ddot{\mathbf{O Z}}$
$\mathrm{Bu}$ çalışma, En ünlü Yemen uydu kanallarının Ramazan ayı boyunca YouTube'daki kendi sitelerindeki görüntüleme oranlarını öğrenmeyi ve bunun nedenlerini anlamayı amaçlamaktadır. $\mathrm{Bu}$ amaca ulaşmak için YouTube'daki tüm Yemen TV kanalları Ramazan'dan bir gün önce ve bir gün sonra incelenmiş, görüntüleme sayıları gözlenmiş, Yemen uydu kanalları ve televizyon yapım şirketlerinden yetkililerle de görüşmeler yapılmıştır. Bu amaçla çalışmada yöntem olarak gözlem ve sonrası derinlemesine görüşmeye dayanan nitel yöntem kullanılmıştır. Ayrıca mevcut 25 Yemen TV kanalı ve bu kanalların Ramazan boyunca YouTube platformunda yayınladığı 17 yerel dizi ve 50'den fazla program arasından, en çok izlenen 10 yerel dizi, 10 program ve en çok izlenen 10 Yemen TV kanalı belirlenmiştir. Yemenlilerin, Ramazan'da yılın geri kalan aylarına göre \%500'e varan artışla daha çok TV izledikleri belirlenmiştir. Çalışma, artan görüntüleme oranının nedeninin Yemen halkının Ramazan'da diğer aylara göre daha fazla boş zamana sahip olmasından kaynaklandığını doğrulamıştır. Bu nedenle Yemenliler televizyon karşısında Ramazan'da daha fazla zaman geçirmiştir.
\end{abstract}

Anahtar Kelimeler: Yemen Uydu Kanalları, Televizyon, Youtube, Drama Dizileri, Programlar

\begin{abstract}
This study aims to identify the average viewing rate of Yemeni satellite channels on their YouTube websites during the month of Ramadan and to determine the reasons for that. In order to achieve this goal, all Yemen TV channels on YouTube were examined the day before and the day after Ramadan, their viewing numbers were observed, and Interviews were also conducted with officials from Yemeni TV channels and production companies. The qualitative approach was used in this study through conducting interviews after observation. The 10 Yemeni television channels were identified from among the 25 channels, the drama series and the programs most viewed on the YouTube platform in Ramadan, as during the month 17 local series and more than 50 programs were shown. It was found that Yemenis watch TV more during the month of Ramadan, with an increase of up to 500\% over the rest of the months of the year. The study confirmed that the reasons for the increased viewing rate were that Yemenis had more free time during Ramadan than during other normal days. Thus they spend this time watching television.
\end{abstract}

Keywords: Yemeni Satellite Channels, Television, Youtube, Drama Series, Programs

\footnotetext{
* Doktora Öğrencisi, Mersin Üniversitesi, Sosyal Bilimler Enstitüsü, Radyo, Sinema ve Televizyon Anabilim Dal1, saddamnadheef@gmail.com, ORCID ID: 0000-0003-3182-9981
} 


\section{GİRIŞ}

Televizyon her evde bulduğu gibi insan hayatının da vazgeçilmez bir parçası haline gelmiştir. Günümüzde televizyonu olmayan bir ev bulmanız çok zordur. İlk kez 1935 'te Almanya'da ortaya çıkıp yayın hizmetine girer girmez insanlar dünyada olup biten her şeyi görmeye, duymaya ve toplumların kültürlerini ve geleneklerini öğrenmeye başladıkça insanların yaşamları büyük ölçüde değişmiştir (Nasr, 2008, s. 223). Bu nedenle televizyon kanalları, halkların kültürlerinin bir yansımasıdır. Teknolojinin gelişmesinin, internetin, akıllı telefonların ve akıllı televizyonların ortaya çıkmasının ardından izleyiciyle televizyon arasında etkileşim başlamıştır. Bu gelişme, TV kanallarının çoğunun internet üzerinden de yayın yapabilmesini sağlamıştır. Bugün uydular üzerinden yayın yapmayan sadece web sitelerinde ve YouTube, Facebook gibi sosyal ağlarda bulunan kanallar vardır. Bu erişim kolaylığı ve internet üzerinden yayın yapmanın düşük maliyeti gibi çeşitli nedenlerden kaynaklanmaktadır.

Tanınmış küresel platform YouTube'da neredeyse çoğu TV kanalının YouTube üzerinden doğrudan yayın yaptığı veya haberler, programlar, filmler, dizi bölümleri vb. paylaştığı söylenebilir. Araştırma alanımız olan Yemen'de, tüm devlet ve özel TV kanalları, izleyicilerin istediği zaman erişebilmesi ve YouTube şirketinin sunduğu reklam gelirlerinden kâr elde etmek için içeriklerini YouTube platformunda paylaşır. Yemen'deki savaş ve ülke genelinde devam eden elektrik kesintileri nedeniyle Yemenli izleyiciler kendilerini YouTube platformunda bulmaktadırlar. Genelde Ramazan ayı boyunca Yemenli TV kanallarının izleyici sayıları artarken, sadece Ramazan ayında sosyal ve eğlence programları ve dizileri üretmekle sınırlı olan bu kanalların sayıları 25'e ulaşır (Watania, 2020).

$\mathrm{Bu}$ çalışmanın problemi, Yemen televizyon kanallarının Ramazan ayında izlenme oranlarının artışıdır. Bu çalışma, YouTube platformu üzerinden Ramazan ayı boyunca en çok izlenen Yemen uydu kanallarını öğrenmeyi ve artan izlenme oranının nedenlerini ortaya çıkarmayı amaçlamaktadır. Bu amaçla aşağıdaki sorulara cevap aranmaktadır:

1. Ramazan ayında YouTube'da en çok izlenen Yemen televizyon kanalları hangileridir?

2. Ramazan ayında YouTube'daki Yemen TV kanallarının en çok izlenen programları ve dizileri hangileridir?

3. Ramazan ayında Yemen TV kanallarının yılın geri kalan aylarıyla karşılaştırılarak izlenme yüzdesi nedir?

4. Ramazan ayında Yemen TV kanallarının izleme oranları neden artıyor? 
5. Yemenli TV kanalları Ramazan ayında program ve dizi üretimini neden artırıyor?

6. Ramazan ayında Yemen TV kanallarının izleyici sayısındaki artışın ve yılın geri kalan aylarında izleyici sayısının azalmasının olumlu ve olumsuz etkileri nedir?

$\mathrm{Bu}$ çalışmanın önemi, kanalların fazla sayıda izleyiciye ulaşmasına ve bu sayede Yemen'de televizyon yapımının gelişmesine katkı sağlayacak olmasından kaynaklanmaktadır. Bu çalışma, Yemen'deki iletişim fakültelerine ve genel olarak Yemen ve Türk kütüphanelerine yeni bir nitel çalışma olarak eklenecektir. Bu konuya odaklanarak sonraki yapılacak çalışmalarda bundan yararlanmak için diğer araştırmacılar tarafından alınabilecek bir referans olarak da düşünülebilir. Çünkü daha önce ulaşılamayan bilgiler sağlanacaktır.

$\mathrm{Bu}$ çalışmada, verilerin nicel analizine ek olarak nitel bir araştırma yöntemi olan yarı yapılandırılmış derinlemesine görüşme tekniği kullanılmıştır. Nitel araştırmalar; gözlem, görüşme ve belgeleri analiz etme gibi nitel bilgileri toplama tekniğidir. Aynı zamanda doğal ve gerçek bir üslupla olay ve analizlere 1şık tutmaktadır (Yıldırım ve Şimşek, 2011, s. 39). Günümüzde sosyal bilimlere ait araştırmalarda görüşme teknikleri geniş şekilde kullanılmaktadır. Esnek gözlem yöntemine sahip bu teknikle saha taramasından doğan kusurlar büyük oranda giderilmektedir. Aynı zamanda bilgiler daha derin bir şekilde toplanır. Yöneltilen kapsamlı ve derin soruların cevaplarıyla daha güvenilir bilgiler elde edilir (Güven, 2001, s. 169). Bu teknik sayesinde araştırmanın konusuyla ilgili derin bilgiler elde edilmiştir. Bu şekilde okurun konuya ilişkin detaylı bilgilere ulaşabilmesi hedeflenmektedir.

Bu çalışma, YouTube'daki Yemen TV kanallarını kapsamaktadır. Çalışmanın amacına ulaşmak için amaçlı örneklem kullanılmıştır. Araştırmacı tarafından kullanılan amaçlı örneklemde dahil olmak üzere istatistikte kullanılan belirli örneklem çeşitleri vardır. Araştırmacı, çalışmalarının amacına ulaştığını anlarsa, bu örneklemin parçalarını veya bireylerini amacına uygun olarak seçer (Nouh, 2006, s. 16). Bunun için en önde gelen Yemen televizyon kanallarından 5 yetkili seçilerek görüşmeler yapılmıştır. Yemenli Televizyon kanallarının, programlarının ve dizilerinin izlenme sayıları da YouTube platformu üzerinden gözetilmiştir.

\section{YEMEN TELEVIZYON KANALLARI}

Yemen, 1964'te Aden'deki (Eski Güney Yemen) İngiliz işgalcilerin bir televizyon yayın istasyonu kurmasıyla televizyon yayınlarıyla tanışmıştır. Arap televizyon kanalları arasında kuruluş sırası bakımından onuncu sırada yer almaktadır (El-Ağberi, 2014, s. 202). 
Aden'i işgal eden İngilizler, işgali reddeden güneydeki halka seslerini ulaştırmak için televizyon kanalı kurmuştur. Aden Güney Arap Birliği Televizyonu olarak adlandırılan kanalda programlar Arapça ve İngilizce dilleriyle yayınlanmıştır. Aynı yıl 11 Eylül'de günlük 8 saat sinyal göndermeye başlamıştır. Yayınları Aden'in kolonisiyle ve bazı komşu alanlarla sınırlı kalmıştır. İngiliz sömürge güçleri 30 Kasım 1967'de güney Yemen'den ayrılmıştır ve televizyon yayını bu tarihten sonra seksenlerin başına kadar devam etmiştir. Aden televizyonu 2 Mart 1981'e kadar yayınını siyah beyaz olarak yapmıştır. Televizyon tarihinde yeni bir merhale sayılan renkli yayın, Aden şehrinde kademeli bir şekilde gerçekleştirilmiştir (Ez-Zelb, 2003, s. 729).

Eski Kuzey Yemen'de televizyon yayını 1974 yılının başlangıcına kadar bilinmemekteyken, Sanaa'da televizyon yayın istasyonu projesi tamamlandığında Birleşik Arap Emirlikleri'nin finans desteğiyle "Sanaa Televizyonu" kurulmuştur. Televizyon yayını 26 Eylül 1975 'te siyah beyaz olarak başlamıştır. Bu şekilde siyah beyaz yayın dört yıl boyunca devam etmiştir. Yayın kapsamı sadece Sanaa ve çevresiyle sınırlıdır. 1979'da Sanaa Televizyonu ilk renkli yayınını yapmıştır (Al-Mutawakil, 1983). Televizyon yayını seksenli yıllarda Sanaa televizyonunda dikkat çekici gelişmelere şahit olmuştur. Öyle ki Yemen Cumhuriyeti topraklarının çoğuna yayın yapılmış ve günde on yedi saate kadar yayın yapabilir hale gelmiştir (Fanack, 2017, s. 11).

\subsection{Yemen Radyo Televizyon Genel Kurumu ve Uydu Yayıncılığına Geçiş Aşaması}

1990'da Kuzey ve Güney Yemen'in birleşmesi ve Yemen Cumhuriyeti'nin kurulmasından sonra, Sanaa'daki Yemen Radyo Televizyon Genel Kurumu ve Aden Radyo ve Televizyon Heyeti tek bir kuruluş altında birleştirilerek Yemen Radyo Televizyon Genel Kurumu adını almıştır. Sanaa istasyonu birinci kanal, Aden istasyonu da ikinci kanal olarak adlandırılmıştır.

Televizyon sektöründeki gelişmelerle 1996'da birinci kanalın programları uydu yoluyla yayınlanmaya başlamıştır. Böylece Yemen dışındaki Arap izleyicisi ilk defa Yemen televizyonunu izleme imkanı bulmuştur. Birinci kanalın programları, ABD uydusu Intelsat 702 üzerinden ve Mısır uydusu Nilesat üzerinden yayınlanmıştır (Ez-Zelb, 2003, s. 737). Bu gelişmelerin sonucu olarak ulusal medya, uydu kanallarının küresel ağına geçmiştir. Uydu kanalı, Orta Doğu'ya ve Avrupa ile Asya'nın bir bölümüne ulaşmıştır. İkinci kanal ise, nüfusun \%60'ına ve Cumhuriyet'in \%65'ine ulaşmak için kapsamını artırmış, iletim hızını günde 9 saate çıkarmıştır (Yemen TV, 2019). 2002'de radyo ve televizyon sayısal uydu yayıncılığına 
geçmiştir. Bu gelişime ayak uydururken 4 kanal haline gelen hükümet kanallarını içeren bir televizyon kompleksi binası inşa edilmiştir (Fanack, 2017, s. 11). Proje; televizyon stüdyoları, galeriler ve bu galerilere ait tesisleri, idari büroları ve televizyon üretimi için temel ihtiyaçların sağlanmasını kapsamaktadır.

\subsection{Kanalların Ortaya Çıkmasıyla Hükümet Kanallarının Sayısının Artırılması}

Yemen'in başkenti Sanaa'da, hükümet kanalları Saba ve Al-İman kurulmuş ve Mart 2008'de uydu yayınları başlamıştır (Yemen TV, 2019). Sonuç olarak, hükümet kanallarının sayısı dört olmuştur: 1)Yemen Kanalı (genel kanal), 2)Aden Kanalı (genel kanal), 3)Saba TV (spor kanalı), 4)Al-İman Kanalı (dini kanal). Tüm bu kanallar karasal ve uydu yayınları, Arabsat, Nilesat, Hotbird ve diğerleri aracılığıyla yayın yapmaktadır. 2007'de kurulan ilk özel kanalın Yemen'de ofisleri olmasına rağmen, özel kanalların Yemen içinden yayın yapmasını yasaklayan bir yasanın varlığı nedeniyle Mısır'dan yayın yapılmıştır (Al-Aghbari, 2016, s. 214). Zamanla işadamlarının veya dış partilerin desteğiyle açılan birçok özel Yemen kanalı ortaya çıkarken, bunların bazıları finansman yetersizliği nedeniyle kapanmıştır. Bugüne kadar kurulan özel kanal sayısı 17'ye ulaşmıştır ve toplamda 25 kanal bulunmaktadır (Watania, 2020).

\subsection{Arap Baharı Devriminden Sonra Yemen Kanallarının Gerçeği}

2011 Devrimi (Arap Baharı), Yemen siyasi güçleriyle görsel medyadaki uydu kanalları arasında program üretim alanında rekabet oluşturmuştur. Ancak 2014'teki darbeden sonra Husi; 4 devlet televizyonunun kontrolünü ele geçirmiş, fikirlerini ve projelerini desteklemeyen özel televizyonları kapatmıştır. 2020'de 4 devlet kanalı, Husi grubuna ait 4 kanal ve yaklaşık 17 özel kanal bulunmaktadır. Bu dört hükümet kanalı, Husi grubu tarafından kontrol edilen kanalların bir kopyasıdır. Meşru hükümet tarafından Yemen dışında yeniden (Suudi Arabistan) açılmıştır ve aynı logo ve kimliği taşımaktadır, ancak çalışanları farklı olduğu gibi medyanın mesajı da öyledir. Husiler, kanallarını Russian Express uydusunda üzerinden Sanaa'dan yayınlarken, hükümet de kanallarını Nilesat ve Arapsat uydusunda yayınlamaktadır. Saddam Al-Nadheef'in (Mayıs 2020) yaptığı araştırmaya göre Yemen hükümeti kanalları Husi devrimcileriyle bağlantılı kanallardan daha fazla desteğe sahiptir ve Yemenliler tarafindan iki kat daha fazla izlenmektedir (Alnadheef, 2020).

Husi grubu tarafından, sesli ve görsel özel medya kuruluşlarına sahip olma hakkına izin verilmemiş olup sadece gazete yayınlama yetkisine izin verilmiştir. Bazı kanallar kapılarını kapatmış ve bazıları ise tamamen kaybolmuştur. Bunun nedeni yeterli destek alamamalarıdır. 
Öte yandan hala varlığını sürdürebilen ve Yemen dışından yayın yapan özel kanallarının tümü, başarılı birer model olarak kabul edilir. Bugün bu kanallar Nilesat, Arabsat ve Express uyduları üzerinden yayınlanmaktadır ve YouTube'da siteleri ve Facebook'ta hesapları vardır. Ancak gösterilen görüntülenme ve abone sayılarına göre YouTube'da Facebook'tan daha popülerlerdir. Bazı YouTube kanallarının abone sayıları bir milyondan fazla kişiye ulaşır ve yayınlanan bazı videolar bir hafta içinde bir milyon kez izlenmektedir. Bu nedenle, bazı kanallar doğrudan uydunun yanında YouTube üzerinden yayın yapmaktadır, bazıları ise tüm içeriklerini yalnızca YouTube üzerinden paylaşmaktadır. $\mathrm{Bu}$ içerik, herhangi bir nedenle evinde televizyon izleyemeyen izleyicilerin takip ettiği çeşitli haberler, raporlar, programlar, diziler vb. içermektedir. Yemen'de internet üzerinden en çok görüntülenen video sitesi YouTube, yedi y1ldır iç savaş yaşayan toplam 30 milyonluk Yemen nüfusundan yaklaşık 2 milyon aboneye sahiptir (Yicon, 2019, s. 62).

\section{YOUTUBE}

Teknolojinin gelişmesi ile birlikte yepyeni iletişim ve medya araçları ortaya çıkmış; özellikle son on yılda sosyal medya uygulamaları bu gelişmelerin en önemli ve etkili unsurları olmuştur. Kaplan ve Haenlein sosyal medyayı, "Web 2.0 teknolojilerinin temelleri üzerine kurulan ve içeriğinin kullanıcılar tarafından oluşturulup değiştirilmesine izin verilen internet tabanlı uygulamalar” şeklinde tanımlanmıştır. Her ne kadar birbirinden farklı özellik gösteren birçok sosyal medya platformu olsa da bir video paylaşım sitesi olan YouTube günümüzün en popüler ve en çok kullanılan sosyal medya araçlarının başında gelmektedir. YouTube, sosyal ağların özelliklerini kullanarak, kişilerin ve kurumların, diğer kişiler için video içerikleri üretmesini ve bu içeriklerin dağıtılmasını mümkün kılmaktadır (Kaplan ve Haenlein'dan akt. Çiçek, 2018, s. 164).

YouTube (https://www.youtube.com/), 2005 yılında üç eski PayPal çalışanı olan Jawed Karim, Chad Hurley ve Steve Chen tarafından televizyonda kaçırdıkları ve yeniden izlemek istedikleri programları izlemek amacıyla ABD'de kurulmuştur. 2006 yılında Google tarafından alınana kadar küçük bir şirket iken bu satın alım ile birlikte YouTube hızla büyümüş ve popülerleşmiştir (Yıldırım, 2018, s. 149). Youtube, video paylaşımına ve arama motoruna sahip özel bir web sitesidir (Gönenli ve Hürmeriç, 2012, s. 220). Alexa'ya göre, 2009 yılında Google sitesinden sonra ikinci büyük arama motoru olmuştur (Alexa, 2018). Youtube, internette video izlenebilecek en büyük platformdur. Ayrıca müzik videoları, filmleri, video blogları ve diğer 
eğitim videoları ve bunun yanında kullanıcılar ve şirketler tarafından oluşturulan çok çeşitli medya içerikleri de içermektedir (Statista, 2018).

Site, videoları yüksek kalitede izlemeyi sağlayan Adobe Flash teknolojisine dayanmaktadır (El-Haşimi, 2018, s. 18). YouTube kendi sitesinde şu şekilde tanıtılmaktadır: "Misyonumuz, herkese sesini duyurma ve dünyayı tanıma şansı vermektedir. Herkesin kendi tarzını yansıtabilmesi gerektiğine; dinlediğimizde, paylaştığımızda ve hikayelerimizle birbirimize bağlandı̆̆ımızda dünyanın daha güzel bir yer olacă̆ına inanıyoruz." Youtube ifade özgürlüğü, bilgi edinme özgürlüğü, firsat özgürlüğü ve aidiyet özgürlügünün temel değerleri olduğunu da sitesinde açıklamıştır (Youtube, 2018).

\subsection{Dünyadaki Youtube Kullanım Oranı}

YouTube, en büyük internet şirketlerinden biri olan Google tarafından satın alındıktan sonra hızla artan kullanıcı sayısıyla günümüzde en fazla aktif kullanıcıya sahip video paylaşım sitesi olmayı başarmıştır. YouTube kullanıcıları yılda 46.000 yıl değerinde içerik üretmektedir. Ayrıca 90'dan fazla ülkede YouTube'da her gün ortalama bir milyar saatlik video izlenmektedir (YouTube, 2018). We Are Social raporuna (2021) göre Youtube aylık kullanıcı sayıs1 1.9 milyardır. Dünya'daki internet kullanıcılarının \%79'u Youtube'a kayıtlıdır ve Youtube’u ziyaret eden aktif kullanıcılar ise bu nüfusun \%86'sını oluşturmaktadır. Buradaki en büyük etken, Youtube'un, Google veya başka bir arama motoru sonuçlarında da çıkabilmesidir. Kayıtlı kullanıcı olmadan da Youtube'u kullanmak mümkün olduğu için Facebook’a göre ziyaretçi sayısı daha fazladır.

World Stats 2020 web sitesinde yayınlanan küresel rakamlara göre, tahmini 4,8 milyar internet kullanıcısından, 4,14 milyarı sosyal medyayı kullanmaktadır. Toplam dünya nüfusu 7,81 milyardır ve dünyada cep telefonu kullananların sayısı 5,20 milyardır. HootSuite ve WeRSocial ortaklığıyla hazırlanan Ekim 2020 Dünya Dijital Raporu'na göre dünya sosyal medyada fazla zaman geçirmekte ve ortalama bir kullanıcı uyanık hayatının yaklaşı \%15'ini sosyal platformları kullanarak geçirmektedir. Bu rakamlar, YouTube'un ne kadar popüler olduğunu ve dünyanın neredeyse dörtte birinin YouTube kullandığını kanıtlar niteliktedir.

\subsection{YouTube'un Kullanım Amaçları}

YouTube, medya kurumları veya uydu kanalları ve gazetecilerle sınırlı olmayıp halkın farklı yaş gruplarında bulunanların, özellikle gençlerin kullanımına da açık haldedir. Aynı zamanda her yaştan ve farklı ilgi alanından milyonlarca insanın hayatlarının ayrılmaz bir 
parçası haline gelmiştir (İman ve Marzouki, 2009, s. 43). YouTube video paylaşım sitesinin amaçları şu şekilde sıralanabilmektedir:

- Kullanıcıların kendi yayınlarını yapmalarına olanak sağlamak,

- Kullanıcıların arasında iletişim kanalı oluşturmak,

- Yüklenilen videoların tüm dünyayla paylaşılmasına olanak sağlamak,

- Yeni insanları tarzları sayesinde tanımaya olanak sağlamak,

- Akademik ihtiyaçları karşılamak için olanak sağlamak,

- Video hakkında yorum ortamının etkisiyle tartışma ve fikir paylaşımını sağlamak,

- Kullanıcıların boş zamanlarını eğlenceli şekilde geçirmelerini sağlamak,

- Kullanıcıların ilgilerine uygun videoları bulmalarını sağlamaktır (Alper'den akt. Çalapkulu ve Şimşek, 2018, s. 271).

\section{BULGULAR VE YORUMLAMA}

$\mathrm{Bu}$ araştırmada, verilerin nicel analizinin yanı sıra görüşme ve gözlemler yapılarak nitel yöntem kullanılmış ve araştırmanın amaçlarına ulaşmak için amaçlı örneklem kullanılmıştır. Araştırma, araştırmacının belirlediği altı soruya cevap bulmak ve çalışmanın amaçlarına ulaşmak için iki yönlü yürütülmüştür.

İlk olarak YouTube'daki sayıları 25 olan tüm Yemen TV kanallarının kapsamlı bir incelemesi yapılmıştır. Her bir kanalın görüntülenme sayıları, Ramazan ayının 30 günü boyunca izlenme sayılarını belirlemek ve ölçmek için Ramazan'dan bir gün önce ve Ramazan'dan bir gün sonra hesaplanmıştır. Böylece, Ramazan ayında YouTube'da en çok izlenen Yemen kanalları belirlenmiştir. Görüntüleme sayısına göre mevcut 25 kanaldan yüzde 40’ını oluşturan ilk on kanal seçilmiştir. Programlar ve dizilerin izlenme sayılarını ölçmek için Yemen kanallarının program haritasına YouTube üzerinden ulaşılmıştır. YouTube'da 17 Ramazan dizisi ve 50'den fazla din, eğlence vb. program bulunmuştur. Yemen kanallarında yer alan Ramazan dizisi ve programları, Ramazan'daki gün sayısına göre, 30 bölümden oluşmaktadır. Ramazan ayında Yemen kanallarının izlenme oranını yılın geri kalan ayları ile karşılaştırarak öğrenmek için, geçen yıl aynı araştırmacı tarafından yapılan bir önceki çalışmaya erişilmiştir (Alnadheef, 2020). Böylelikle 24 Mayıs 2020'de, Ramazan ayından bir gün sonra, gözlemlenen her bir kanaldaki izlenme sayısına ilişkin veriler alınmıştır.

Araştırmanın ikinci aşamasında, önde gelen kanallardan beş gazeteci, yapımcı ve yetkili ile röportajlar yapılmıştır. Sorular kendilerine WhatsApp üzerinden Arapça gönderilmiştir. Bir 
hafta sonra araştırmanın son üç sorusuna ilişkin tüm cevaplar alınmış ve bu cevaplar çalışmanın diline (Türkçe) çevrilmiştir. Böylelikle, hem Ramazan ayında Yemen kanallarının dizi ve program üretiminin yılın geri kalan aylarına göre artmasının hem de Yemen halkının Yemen televizyon kanallarını Ramazan ayında yılın geri kalan aylarından daha fazla izlemesinin nedenleri öğrenilmiştir. Ayrıca Ramazan ayı boyunca Yemen kanallarının, dizilerinin ve programlarının artan izlenme sayılarının olumlu etkileri ve Ramazan dışında izlenme sayılarının azalmasının olumsuz etkileri de öğrenilmiştir. Burada elde edilen bilgiler, bir sonraki bölümde değineceğimiz gibi, görüşmeye katılan uzmanların bakış açılarna dayanmaktadır.

\subsection{Ramazan Ayında YouTube'da En Çok İzlenen Yemen Televizyon Kanalları}

Ramazan ayı boyunca en çok izlenen on Yemen uydu kanalına değinmeden önce, bu çalışmada, aşağıdaki tabloda gösterildiği gibi bu kanalların YouTube'a katıldıkları tarihler şu şekildedir:

Tablo 1. Youtube'daki Yemen Televizyon Kanallarının Linkleri ve Katılımları Tarihleri

\begin{tabular}{|c|l|c|l|}
\hline Sira & Kanal Adı & $\begin{array}{c}\text { Youtube'a } \\
\text { Katılması } \\
\text { Tarihi }\end{array}$ & \multicolumn{1}{c|}{ Youtube'teki Kanal Linki } \\
\hline $\mathbf{1}$ & Yemen Shabab & 18.10 .2011 & $\underline{\text { https://www.youtube.com/c/yemenshabab/about }}$ \\
\hline $\mathbf{2}$ & AlSaeedah & 11.01 .2011 & https://www.youtube.com/c/alsaeedahchannel/about \\
\hline $\mathbf{3}$ & Al Mahriah & 16.10 .2019 & $\underline{\text { https://www.youtube.com/c/AlmahriahTV/about }}$ \\
\hline $\mathbf{4}$ & Hadhramaut & 04.06 .2015 & $\underline{\text { https://www.youtube.com/c/hadramouttv/about }}$ \\
\hline $\mathbf{5}$ & Suhail & 07.11 .2011 & $\underline{\text { https://www.youtube.com/c/SuhailChannel1/about }}$ \\
\hline $\mathbf{6}$ & Al Hawyah & 19.10 .2017 & $\underline{\text { https://www.youtube.com/c/alhawyahchannel/about }}$ \\
\hline $\mathbf{7}$ & $\begin{array}{l}\text { Yemen (Husi'ye } \\
\text { ait) }\end{array}$ & 08.10 .2019 & $\underline{\text { https://www.youtube.com/c/YementvfromYemen/about }}$ \\
\hline $\mathbf{8}$ & Belqees & 23.03 .2015 & $\underline{\text { https://www.youtube.com/c/BelqeesTV/about }}$ \\
\hline $\mathbf{9}$ & $\begin{array}{l}\text { Al-Ghad Al- } \\
\text { Moshreq }\end{array}$ & 01.05 .2016 & $\underline{\text { https://www.youtube.com/c/alghadye/about }}$ \\
\hline $\mathbf{1 0}$ & Al Masirah & 29.09 .2017 & $\underline{\text { https://www.youtube.com/c/Hona Almasirah3/about }}$ \\
\hline
\end{tabular}

Ramazan ayı boyunca YouTube'da Yemen uydu kanallarını izleyenlerin sayısını öğrenmek için; YouTube'da bulunan 25 Yemen TV kanalının görüntülenme sayıları da gözlemlemiştir. Gözlem; 13 Nisan 2021'de, Ramazan ayının ilk günü, 00.00 - 01.00 saatleri arasında gerçekleştirilmiştir. Ardından araştırmacı bir ay sonra, Ramazan'ın son günü, 13 Mayıs 2021'de aynı saatte gözlemi tekrarlamıştır. Ramazan ayının 30 günü boyunca iki dönem arasındaki görüntüleme sayısını hesaplamıştır. İlk on kanal için sayma sonuçları aşağıdaki gibidir: 
Tablo 2. Ramazan ayı Boyunca YouTube'da En Çok İzlenen Yemen Televizyon Kanalları

\begin{tabular}{|c|l|c|c|c|}
\hline Sıra & Kanal Adı & $\begin{array}{c}\text { Ramazan'ın İlk } \\
\text { Günü } \\
\text { Görüntüleme } \\
\text { Saysı }\end{array}$ & $\begin{array}{c}\text { Ramazan'ın Son } \\
\text { Günü } \\
\text { Görüntüleme } \\
\text { Saysı }\end{array}$ & $\begin{array}{c}\text { Ramazan Ayı } \\
\text { Boyunca } \\
\text { Görüntüleme } \\
\text { Sayısı }\end{array}$ \\
\hline $\mathbf{1}$ & Yemen Shabab & 443.918 .335 & 478.502 .709 & 34.584 .374 \\
\hline $\mathbf{2}$ & AlSaeedah & 331.860 .846 & 360.975 .682 & 29.114 .896 \\
\hline $\mathbf{3}$ & Al Mahriah & 30.317 .329 & 48.225 .045 & 17.853 .716 \\
\hline $\mathbf{4}$ & Hadhramaut & 47.773 .283 & 59.189 .648 & 11.416 .365 \\
\hline $\mathbf{5}$ & Suhail & 256.995 .729 & 268.065 .545 & 11.069 .816 \\
\hline $\mathbf{6}$ & Al Hawyah & 55.890 .800 & 62.559 .831 & 6.669 .031 \\
\hline $\mathbf{7}$ & $\begin{array}{l}\text { Yemen (Husi'ye } \\
\text { ait) }\end{array}$ & 1.268 .022 & 4.940 .626 & 3.672 .604 \\
\hline $\mathbf{8}$ & Belqees & 71.370 .179 & 73.437 .350 & 2.067 .171 \\
\hline $\mathbf{9}$ & $\begin{array}{l}\text { Al-Ghad Al- } \\
\text { Moshreq }\end{array}$ & 47.217 .475 & 49.097 .155 & 1.879 .680 \\
\hline $\mathbf{1 0}$ & Al Masirah & 26.277 .572 & 27.800 .614 & 1.523 .042 \\
\hline
\end{tabular}

Yukarıdaki tabloya göre en rekabetçi ilk beş kanalın ilki Yemen Shabab kanalı iken, AlSaeedah ikinci, Al Mahriah üçüncü, Hadhramaut dördüncü ve Suhail kanalı beşinci olmuştur. Ondan sonra tabloda belirtilen diğer kanallar gelmiştir. Tamamı özel olan bu kanalların özellikle ilk üçü, Ramazan ayında görüntülenmek ve izleyiciyi çekmek için daha yoğun çalışmıştır. Her kanalda ortalama iki drama dizisi, dört eğlence, dini ve çeşitli programlar yayınlanmıştır. İzleyici sayısı açısından Yemen Shabab ve A1Saeedah kanalı, üçüncü sıradaki Al Mahriyah kanalının çok önündedir ve bu muhtemelen her birinin YouTube kanalında bir milyondan fazla abonesi olan bu iki kanalın kuruluşunun daha eski olmasından kaynaklanmaktadır. Geri kalan beş kanal yukarıdaki tabloda gösterilmektedir.

Şekil 1'de yer alan grafik, kanal başına görüntülenme sayısı arasındaki farkları göstermektedir. $\mathrm{Bu}$ kanallardan bazıları abone sayısını artırmayı YouTube'daki görüntülemelerin sayısını artırmanın bir ölçüsü olarak düşünmektedir. Ancak bu aynı zamanda yayın yapılan içeriğin türüne de bağlıdır. Öte yandan, herhangi bir kanalın çok sayıda abonesi varsa bu, şüphesiz izleyicinin istenen içeriği sağladığı anlamına gelmektedir. Aksi takdirde izleyicinin kanala abone olması beklenemez. 


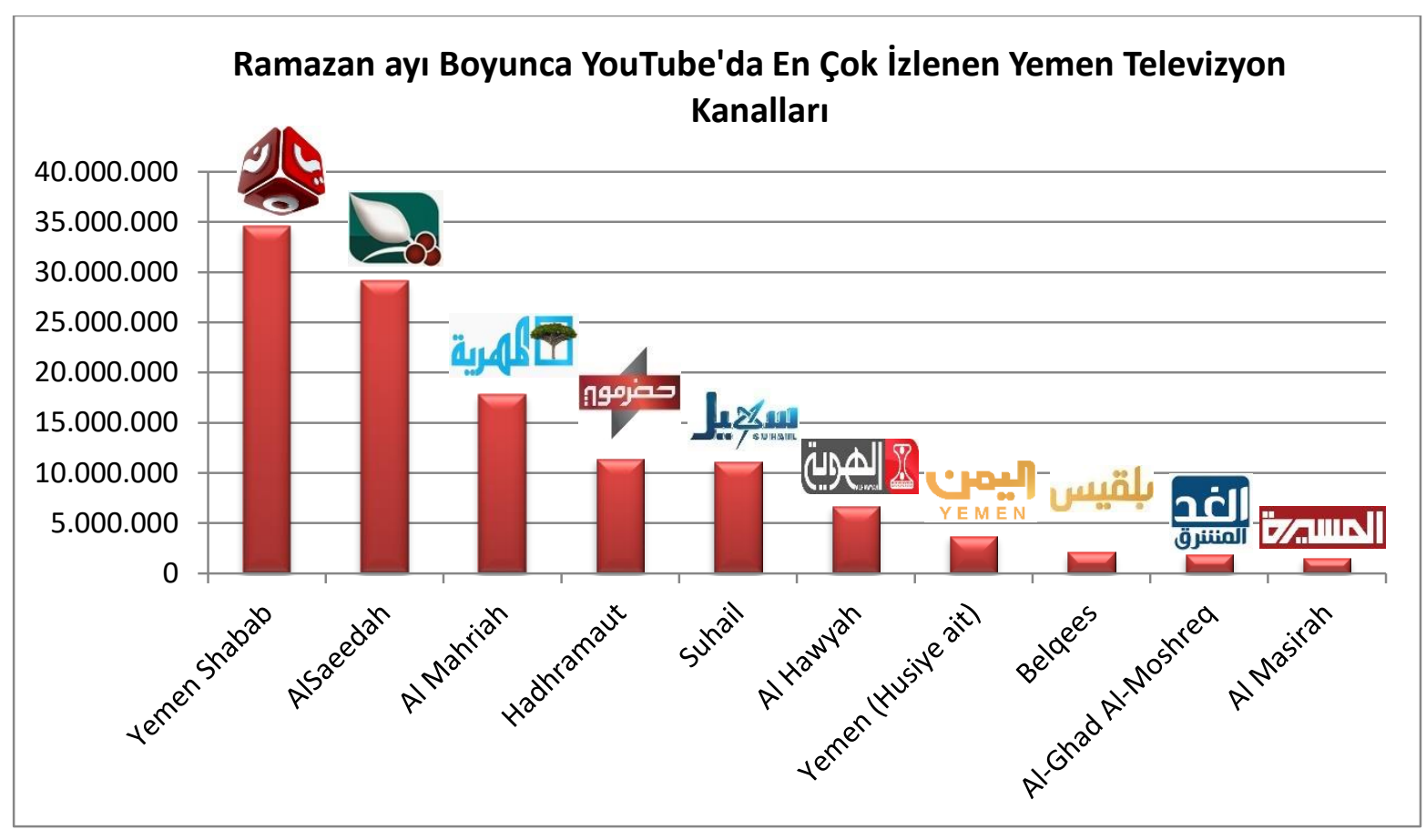

Şekil 1. Ramazan ayı Boyunca YouTube'da En Çok İzlenen Yemen Televizyon Kanalları

Aşağıdaki tablo Ramazan sezonu boyunca en çok izlenen kanallarla artan abone sayılarını göstermektedir:

Tablo 3. YouTube'daki İlk On Sirada Gelen Yemen Televizyon Kanalına Abone Sayıs1

\begin{tabular}{|c|c|c|c|c|}
\hline Sira & Kanal Adı & $\begin{array}{c}\text { Ramazan'ın İlk } \\
\text { Günü Abone } \\
\text { Saysı }\end{array}$ & $\begin{array}{c}\text { Ramazan'ın Son } \\
\text { Güinü Abone } \\
\text { Saysı }\end{array}$ & $\begin{array}{c}\text { Ramazan Ayında } \\
\text { Artan Abone } \\
\text { Sayısı }\end{array}$ \\
\hline 1 & AlSaeedah & $961 \mathrm{Bin}$ & 1.04 Milyon & $124 \mathrm{Bin}$ \\
\hline 2 & Yemen Shabab & 1.23 Milyon & 1.34 Milyon & $110 \mathrm{Bin}$ \\
\hline 3 & Al Mahriah & 177 Bin & $274 \mathrm{Bin}$ & 97 Bin \\
\hline 4 & Hadhramaut & 217 Bin & $284 \mathrm{Bin}$ & $67 \mathrm{Bin}$ \\
\hline 5 & Suhail & 706 Bin & $752 \mathrm{Bin}$ & $46 \mathrm{Bin}$ \\
\hline 6 & Al Hawyah & $307 \mathrm{Bin}$ & $336 \mathrm{Bin}$ & 29 Bin \\
\hline 7 & Yemen (Husiye ait) & Göstermiyor & Göstermiyor & Göstermiyor \\
\hline 8 & Belqees & $325 \mathrm{Bin}$ & 367 Bin & $15 \mathrm{Bin}$ \\
\hline 9 & $\begin{array}{l}\text { Al-Ghad Al- } \\
\text { Moshreq }\end{array}$ & $195 \mathrm{Bin}$ & $202 \mathrm{Bin}$ & 7 Bin \\
\hline 10 & Al Masirah & $151 \mathrm{Bin}$ & $155 \mathrm{Bin}$ & $4 \mathrm{Bin}$ \\
\hline
\end{tabular}

Genel olarak toplam abone sayısı açısından Yemen Shabab kanalı birinci, AlSaeedah ikinci olurken, bu iki kanal daha önceki verilere göre en çok izlenen iki kanal olarak öne çıkmıştır. Ramazan ayındaki abone sayısı artışına gelince, bunun tam tersi olmuş, AlSaeedah birinci, Yemen Shabab ikinci sırada gelmiştir. İzleyici sayısındaki artışa paralel olarak Al 
Mahriah üçüncü, Hadhramaut dördüncü ve Suhail beşinci olmuştur. Suhail kanalının 750.000'den fazla abonesi bulunmaktadır ve abone sayısı açısından Yemen Shabab ve AlSaeedah kanallarından sonra gelmektedir, ancak görüntülenme sayısı açısından beşinci sırada yer almıştır. Belqees kanalının da 325.000 abonesi vardır, ancak görüntülenme sayısı açısından sekizinci sırada yer almıştır. Aksine, Al Mahriah kanalının sadece 177.000 abonesi vardır, ancak Ramazan ayında aldığı görüntülenme sayısı açısından üçüncü sırada yer almıştır. $\mathrm{Bu}$, abone sayısının görüntülenme sayısını artırmak için bir kriter olmadığını, daha ziyade izleyici sayısını artıran ve abone yüzdesini yükselten faktörün gösterilen içerik olduğunu doğrular. Bu, Al Mahriah kanalının üçüncü sıradaki kanal olarak abonelerden aldığı artışla fark edilmiştir.

\subsection{Ramazan Ayında Youtube'daki Yemen Televizyon Kanallarının En Çok İzlenen Programlar ve Diziler}

Yemen uydu kanalları arasında drama türünde içerik üretimi açısından büyük bir rekabet yaşanmıştır. Ramazan için çok sayıda dizi üretilmiş ve sayıları 17'ye ulaşmıştır. En yüksek görüntülenmeye göre ilk on dizi şu şekilde olmuştur:

Tablo 4. Yemen TV kanallarının Dizilerinin Youtube'daki Görüntülenmelerine Göre Siralamas1

\begin{tabular}{|c|l|c|c|}
\hline Sıra & Dizi Adı & $\begin{array}{c}\text { Ramazan Ayında } \\
\text { Ortalama Görüntüleme } \\
\text { Saysı }\end{array}$ & Kanal Adı \\
\hline $\mathbf{1}$ & Al-Jahmaliyah Geceleri & 360.852 & Yemen Shabab \\
\hline $\mathbf{2}$ & Güneşin Arkası & 349.666 & AlSaeedah \\
\hline $\mathbf{3}$ & Cappuccino & 283.854 & Yemen Shabab \\
\hline $\mathbf{4}$ & Al-Jamrah-2 (Köz) & 254.099 & Hadhramaut \\
\hline $\mathbf{5}$ & Kahtan'ın Çocukları & 149.439 & Al Mahriah \\
\hline $\mathbf{6}$ & Gidiş Yolculuğu & 129.905 & Al Mahriah \\
\hline $\mathbf{7}$ & Şer Dişler & 107.475 & Yemen (Husiye ait) \\
\hline $\mathbf{8}$ & Mikhlif Saib & 62.810 & AlSaeedah \\
\hline $\mathbf{9}$ & Mimi Kama Wiwa & 21.568 & Al-Ghad Al-Moshreq \\
\hline $\mathbf{1 0}$ & Vatan Bağırışı & 14.782 & Al Hawyah \\
\hline
\end{tabular}

İzleyici sayısı açısından Al-Jahmaliyah Geceleri dizisi birinci, Güneşin Arkası ikinci, Cappuccino üçüncü, Al-Jamrah2 dördüncü ve Kahtan'ın Çocukları beşinci olmuştur. En çok izlenen dizinin en çok görüntülenen kanal olan Yemen Shabab'da yayınlandığı görülmektedir. 
AlSaeedah tarafından yayın yapılan dizi aynı zamanda en çok izlenen ikinci kanalda yer almıştır. Üçüncü sırada yer alan dizi, en çok izlenen kanal olan Yemen Shabab kanalına aittir. Dördüncüsü, izleyici sayısı bakımından dördüncü sırada yer alan kanal olan Hadhramaut kanalında gösterilen dizi gelmiştir. Al Mahriya'da gösterilen dizi en çok izlenen üçüncü kanal olarak beşinci sırada yer almıştır.

Dizilerin geri kalanı, tabloda belirtilen istatistiklere göre diğer kanallara dağıtılmıştır. Dizilerin izleyici sayısı, kanal görüntüleme sayısındaki artışa net bir şekilde yansımıştır. Husi hareketine bağlı olan Yemen Kanalı çok fazla izleyiciye sahip değildir, ancak gösterdiği dizi sayesinde kanal, izleyici sayısı açısından yedinci sırada yer almıştır ve gösterdiği dizinin izlenmesi de yedinci sıradadır. Bunların yanında, ister programların ister dizilerin yapımı düzeyinde olsun, dört devlet kanalı bu rekabette hiç yer almamıştır.

Program düzeyinde ise izleyicileri, reklamcıları ve tüccarları çekmek amacıyla özel kanallar arasında bol miktarda üretim ve yoğun rekabet yaşanmıştır. Bu amaçla 50'den fazla program üretilmiş ve bunlardan en önemlileri en yüksek görüntülenme sayılarına göre aşağıdaki gibidir:

Tablo 5. Yemen TV kanalları Programlarının Youtube'daki Görüntülenmelerine Göre Siralamas

\begin{tabular}{|c|l|c|c|}
\hline Sıra & Program Adı & $\begin{array}{c}\text { Ramazan Ayında } \\
\text { Ortalama Görüntüleme } \\
\text { Saysı }\end{array}$ & Kanal Adı \\
\hline $\mathbf{1}$ & Halk Otobüsü-3 & 107.504 & Al Hawyah \\
\hline $\mathbf{2}$ & Gaga-5 & 93.735 & Suhail \\
\hline $\mathbf{3}$ & Şans Gezisi-3 & 78.186 & Yemen Shabab \\
\hline $\mathbf{4}$ & Alsaeedah Kuşu-3 & 73.514 & AlSaeedah \\
\hline $\mathbf{5}$ & Raghad Tutumları & 63.118 & Al Mahriah \\
\hline $\mathbf{6}$ & Meydan Okuma ve Yüzleşme-2 & 31.595 & AlSaeedah \\
\hline $\mathbf{7}$ & Merhamet Ediniz-5 & 19.662 & AlSaeedah \\
\hline $\mathbf{8}$ & Hoş/sh & 17.256 & Suhail \\
\hline $\mathbf{9}$ & Meydan-6 & 7.256 & Hadhramaut \\
\hline $\mathbf{1 0}$ & Haith ul-İnsan-3 (Insan'da) & 7.254 & Belqees \\
\hline
\end{tabular}

Programlarda izleyici sayısı açısından altıncı sırada olan Al Hawyah kanalında yayınlanan Halk Otobüsü-3 programı ilk sırada yer almıştır. Suhail kanalındaki Gaga-5 programı, kanalın izleyici sayısı açısından beşinci sırada olmasına rağmen ikinci sırada yer almıştır. Sonraki üç program, en çok izlenen ilk üç kanalın izlenme sırasına göre sıralanmıştır. 
Yemen Shabab kanalındaki Şans Gezisi-3 programı üçüncü, AlSaeedah kanalındaki Alsaeedah Kuşu-3 programı dördüncü, Al Mahriya kanalındaki Raghad Tutumları programı ise beşinci olmuştur. Altıncıdan onuncuya kadar olan programlar, Hadhramaut kanalındaki Meydan-6 programı ve Belqees kanalındaki Haith ul-İnsan-3 programı hariç, daha önce belirtilen AlSaeedah ve Suhail kanallarının programlarıdır.

$\mathrm{Bu}$ analiz Ramazan ayında Yemen uydu kanallarında gösterilen 10 dizinin ve 40'tan fazla programın kapsamlı incelenmesinden elde edilmiştir. Ardından Ramazan sezonu boyunca yayınlanan dizi ve programların tüm bölümlerin için görüntüleme sayıları hesaplanmıştır. Araştırmacı bunu toplam izlenme sayısının programın veya dizinin bölümlerinin sayısına bölünmesi ile en çok izlenen programları ve dizileri belirlemek için yapmıştır. Ramazan ayının son gecesi olan 13 Mayıs 2021 Perşembe günü tüm dizi ve programlar 00:00 - 04:00 saatleri arasında gözlenmiştir. ${ }^{1}$

\subsection{Ramazan Ayında Yemen Televizyon Kanallarının Yılın Geri Kalan Aylarıyla Karşılaştırılarak İzleme Yüzdesi}

Yemen'deki pek çok gözlemci, Yemenlilerin Ramazan ayı dışında televizyon izlemediğine inanır ve bu durum, kanalları yılın geri kalan aylarından ziyade özellikle Ramazan ayında yapımla ilgilenmeye itmiş olabilir. Bunu doğrulamak için Ramazan ayında ve Ramazan dışında izleyici ve abone sayısındaki artış oranlarını aşağıdaki tablo üzerinden karşılaştırmıştır:

Tablo 6. Yılın Geri Kalan Aylarına Kıyasla Ramazan Ayında İlk Beş Sırada Gelen Yemenli TV Kanallarının Youtube'da Görüntüleme Sayısı

\begin{tabular}{|l|l|l|l|l|l|l|l|}
\hline Sıra & Kanal Adı & $\begin{array}{l}\text { Ramazan } \\
\text { Dısındaki } \\
\text { Görüntüleme } \\
\text { Sayısı (11 Ay) }\end{array}$ & $\begin{array}{l}\text { Aylık } \\
\text { Ortalama }\end{array}$ & $\begin{array}{l}\text { Ramazan } \\
\text { Ayında } \\
\text { Boyunca } \\
\text { Görüntüleme } \\
\text { Sayısı }\end{array}$ & $\begin{array}{l}\text { Ramazan } \\
\text { Dışındaki } \\
\text { Abone } \\
\text { Sayısı }\end{array}$ & $\begin{array}{l}\text { Aylık } \\
\text { Ortalama }\end{array}$ & $\begin{array}{l}\text { Ramazan } \\
\text { Boyunca } \\
\text { Abone } \\
\text { Sayısı }\end{array}$ \\
\hline $\mathbf{1}$ & Yemen Shabab & 122.511 .803 & 11.137 .436 & 34.584 .374 & 190 Bin & 17.272 & $110 \mathrm{Bin}$ \\
\hline $\mathbf{2}$ & AlSaeedah & 112.360 .848 & 10.214 .622 & 29.114 .896 & $160 \mathrm{Bin}$ & 14.545 & $124 \mathrm{Bin}$ \\
\hline $\mathbf{3}$ & Al Mahriah & 29.807 .344 & 2.709 .758 & 17.853 .716 & 174 Bin & 15.818 & $97 \mathrm{Bin}$ \\
\hline $\mathbf{4}$ & Hadhramaut & 23.546 .427 & 2.140 .584 & 11.416 .365 & $153 \mathrm{Bin}$ & 13.909 & $67 \mathrm{Bin}$ \\
\hline $\mathbf{5}$ & Suhail & 21.567 .114 & 1.960 .646 & 11.069 .816 & $122 \mathrm{Bin}$ & 11.090 & $46 \mathrm{Bin}$ \\
\hline
\end{tabular}

\footnotetext{
2 Örneğin 30 bölümlük bir dizinin veya programın toplam örüntüleme sayısı 10.500'dür. 10.500'ü 30 bölüm sayısına bölerek bölüm başına ortalama olarak 350 bin görüntüleme sayısına ulaşılmıştır.
} 
Araştırmacı bu bölümdeki on kanalın tamamının istatistiklerini elde edememiş, bu nedenle en çok izlenen ilk beş kanalın istatistiklerini kullanmıştır. ${ }^{2}$ Tablodaki rakamlar, Yemenlilerin Ramazan ayında Ramazan ayının geri kalan aylarına göre daha fazla televizyon izlediğini göstermektedir. Ramazan ayında izleyici artış yüzdesi yılın geri kalan on bir ayına göre \%300 ile \%500 arasında, abone artış yüzdesi ise \%450 ile \%850 arasında değişmiştir. Ramazan ayında izleyici sayısındaki artış birkaç nedenden kaynaklanmaktadır.

\subsection{Ramazan Ayında Yemen Televizyon Kanallarının İzleme Oranının Artmasının Nedenleri}

Ramazan ayında Yemen kanallarının izlenme oranının artmasına yol açan pek çok neden vardır ve bunlar, bu araştırmada hedef alınan bazı katılımcılarla görüşülerek onların bakış açısından gözlenmiştir. AlSaeedah uydu kanalının genel müdürü Mohktar Alqadasi, bu nedenleri dört noktada özetlemektedir:

- Bu ayda olă̆anüstü bir üretim olduğunu bilirler,

- İleyicilerin televizyon izlemek için yeterli zamanları vardır,

- Kanallar güçlü içerikte yayın yapmayı isterler,

- Belki de Ramazan'daki üretilen çalışmalarının ve içeriklerin izlemeye değer bulunduğu geçmişten gelen bir gelenek vardır (Mohktar Alqadasi, 12.05.2021).

Yemen Uydu Kanalında gazeteci, eleştirmen ve haber direktörü olan Tawfik Alsharabi ise, Ramazan ayında gecenin daha uzun bir zaman olduğunu ve izleycinin Ramazan dışındaki günlere göre daha fazla program ve dizi izlemesine olanak sağladığını söylemiştir (Tawfik Alsharabi, 10.05.2021).

Genellikle Yemen'de insanlar Ramazan boyunca sabaha kadar bütün gece uykusuz kalırlar. $\mathrm{Bu}$ sürede insanlar toplanıp, televizyon ekranlarından veya YouTube üzerinden program ve dizilerı izlerler. Sabah ya öğleden sonra saat ondan ikiye kadar işe giderler ya da çalışmıyorlarsa uyurlar. Özel işyeri sahipleri ve tüccarlar ise öğle namazından akşama kadar,

\footnotetext{
${ }^{2}$ Yukarıdaki tabloda listelenen veriler, geçtiğimiz yıla ait istatistiklere başvurularak elde edilmiştir. Geçen yıl aynı araştırmacı, 24 Mayıs 2020 Ramazan ayının son gününde Arapça olarak benzer bir çalışma gerçekleştirmiş ve sadece yukarıda belirtilen kanalların bazılarının izleyici ve abone sayılarını belirlemiştir. Geçen yılki araştırmayla ilgili o kanallar, YouTube'da izlenme sayısı açısından bu yıl ilk beşte yer alan kanallarla aynıdır. Ve bu kısımda yukarıdaki ilk beş kanal arasında rakamlar ve sonuçlar yakın olduğu için; diğer tüm Yemen kanallarına genellenebilir. Bkz. https://yeniyemen.net/p-66484
} 
bazen de gece geç saatlere kadar çalışırlar. Bu konuda Belqis uydu kanalının program direktörü Kamal Haydarah, Ramazan ayında insanların Ramazan ayının getirdiği değişikliğe göre yaşam tarzlarını değiştirdiğini söylemiştir.

Ramazan ayında ilgi alanları ve takip ettikleri şeyler değişir, sosyal boyutu olan dizileri ve programları ararlar. Ayrıca, menfaatlerine ve sorunlarına yakın buldukları için Yemen kanallarındaki yerel üretimi takip etmek isterler (Kamal Haydarah, 07.05.2021).

Televizyon yapımcısı olan Saber Al-Jabri, şunları eklemiştir:

"Yemenliler, programatik veya dramatik çeşitli türlerde yerel karakterlerin üretimindeki artış nedeniyle Ramazan ayında yerel kanalları izler. Ve yerel kanallar yıl boyunca ithal konserve içerikleri göstermek için çalıştığ için; Ramazan, izleyiciler için çoğu yerel olarak hazırlanan programları izleme firsatını temsil eder" (Saber Al-Jabri, 05.05.2021).

$\mathrm{Bu}$ tespit bir medya yapım şirketinin sahibi olan Taleb Al-Maamarı tarafından da desteklemektedir. Taleb, Yemen'deki insanların Ramazan ayı boyunca Yemen kanallarını çok izlediğini, çünkü Ramazan dışında kalan aylarda Yemen kanallarının dizi üretmediğini ve yayınlamadığını söylemektedir. Taleb'e göre:

Yemen kanallarının çoğu, Ramazan ayında Yemenli izleyiciyi memnun edecek drama dizileri ve Komedi/eğlencelyarışma programları üretmek için yarışır (Taleb AlMaamarl, 11.05.2021).

Bahsedilen görüşlerden yola çıkarak, Ramazan ayında YouTube'daki Yemen uydu kanallarının izlenme oranlarının artmasının sebebinin Ramazan ayında Yemen kanallarının dizi ve program üretimindeki artışın bir sonucu olduğu söylenebilir. Ayrıca Ramazan ayında Yemenlilerin yılın geri kalan aylarına göre daha fazla televizyon izlemesi için yeterli zamanın olması da sebeplerden bir tanesidir. Bir diğer önemli sebep Ramazan'da televizyon kanalların dizi ve program yapmak için birbiriyle rekabet etmesidir ve bu da izleyiciyi yerel kanallara çeker.

\subsection{Yemenli Televizyon Kanallarının Ramazan Ayında Program ve Dizi Üretiminin Artması}

Yapılan gözlemlerden yola çıkarak, Yemen TV kanallarının Ramazan ayı içinde Ramazan dışında ürettiklerinden daha fazla üretim yaptıklarını ve bunun AlSaeedah uydu 
kanalının genel müdürü Mohktar Alqadasi'nin belirttiği gibi, birkaç faktörden kaynaklandığı söylenebilir:

- Kanallar geniş bir izleyici kitlesi olduğunu bilirler ve bu nedenle izleyiciyi çekmeyi amaçlayan içerikleri yayınlamak için çalışırlar.

- Ramazan ayl, reklam ve sponsorluklar için büyük bir pazar olarak kabul edilir ve bu nedenle çok sayıda program ve dizi gösterilmelidir.

- İlenmeyi artırmak için kanallar arasında bulunan rekabettir (Mohktar Alqadasi, 12.05.2021).

Belqees uydu kanalının program direktörü Kamal Haydarah'ya göre Ramazan ayının gelişiyle birlikte izleyicinin yaşantılarında bir değişiklik yaşanır ve bu nedenle kanallar bu ay boyunca izleyici çekmeye yatırım yapmak için bu değişime ayak uydurmaktadır. Bu değişim Ramazan ayında yılın geri kalanına göre artan üretime de yansır ve bu sadece Yemen kanallarıyla sınırlı kalmayıp bir Arap geleneği haline gelmiştir (Kamal Haydarah, 07.05.2021).

Yemen Uydu Kanalında gazeteci, eleştirmen ve haber direktörü olan Tawfik Alsharabi, Ramazan ayında kanalları daha sık izlemeye alışmış olan izleyicilerin ihtiyaçlarını karşılamak için Yemen uydu kanallarının Ramazan ayında program üretimlerini artırdığını düşünüyor. Ayrıca, reklamveren veya tüccar, ürünlerini tanıtma ve böylece bu dizilerin yapımını finanse etme firsatı bulur. Ramazan ayında yüksek oranda TV izlenmensinin bir başka nedeni de, herkesin maddi ödül kazanmak için katılmak istediği yarışma programlarının bulunmasıdır (Tawfik Alsharabi, 10.05.2021).

Taleb Al-Maamari bir TV yapımcısı olarak Ramazan'ı Yemenli kanallar için bir sezon olarak görüyor. Bu ay televizyon içeriği üretimindeki artışın, Ramazan ayı boyunca gösterilen dizi ve programlara ürünleri için reklam gösterilmesi karşıllı̆ında sponsorluk yapan finans şirketleri ve tüccarların varlığından kaynaklandığını açıklıyor (Taleb Al-Maamarı, 11.05.2021).

Yemen'de Ramazan ayında, özellikle Ramazan Bayramı'nın yaklaşmasıyla birlikte insanlar alışverişe çıkarlar ve yılın geri kalan aylarından daha fazla kıyafet, gıda, kişisel ve ev eşyaları alır. Bu nedenle Ramazan ayı alışveriş ve harcama için özel bir firsattır. Birçok kanalın yapımcısı olan Saber Al-Jabri, Ramazan'ın tüm yerel kanallar için bir sezon olduğunu ve bu nedenle kanalların izleyicileri çekmek için çalıştığını düşünmektedir. Saber, Ramazan ayında gündüzleri Yemenlilerin çoğunluğu için aktivitenin azaldığını ve vatandaşlar için bunun bir oruç, zikir ve rahatlama ayı olarak kabul edildiğini, bu nedenle çoğu insanın gece uyumadığını 
ve TV ekranlarının önünde kaldığını söylemiştir. Kanalların izleyicilerin ilgisini çekmek için yerel programları ve dizileri kullanması bu nedenden kaynaklanmaktadır (Saber Al-Jabri, 05.05.2021).

Buraya kadar söylenenlerden Ramazan ayında artan televizyon izleme oranları ile artan içerik üretimi arasında bir ilişki olduğu sonucuna varılabilir. Ramazan ayı, özellikle gıda maddelerinin çok tüketildiği bir ay olmasının yanı sıra, Müslümanlar için iki dini vesile olan Ramazan Bayramı ve Kurban Bayramı'ndan önce gelmektedir. Bu nedenle, tüccarlar ve şirketler ürünlerinin reklamını yapmaya çalışırlar ve bu da, kanalları, finansmanı sponsorlara (tüccarlar) bağlı olan dizi ve eğlence programları üreterek kâr etmeye teşvik eder. Ayrıca, yapım için kanallar arasındaki rekabet, bu ay boyunca her kanalın elinden gelenin en iyisini yapmasını sağlamaktadır.

\subsection{Ramazan Ayında Yemen Kanallarının İzleyici Sayısındaki Artışın ve Yılın Geri Kalan Aylarında İzleyici Sayısının Azalmasının Olumlu ve Olumsuz Etkileri}

Ramazan ayında yerel TV izleme hacminin artmasının hem kanallar hem de izleyiciler için olumlu etkilerinin yanında diğer aylardaki izlenme sayısındaki azalmanın da olumsuz etkileri vardır. Olumlu etkileri Mohktar Alqadasi aşağıdaki üç noktada özetlerken, olumsuz etkiler bunların tam tersidir.

- Reklamların ve kaynakların hacim artışı ve böylece içerik üretiminin artışı,

- İleyicilerin çekilmesi ve böylece yll boyunca izlenme hacminin artışı,

- Rekabet, yapımin seviyesinde ve gelişiminde bir artışa yol açar ve bu izleyici açısından faydalıdır. (Mohktar Alqadasi, 12.05.2021).

Kamal Haydarah, TV kanallarının Ramazan ayında güçlü bir yapım sağlamak için çalışmasını ve böylece takipçi kitlesini artırmasını olumlu bir etki olarak görmektedir. Ayrıca Ramazan ayında kanalların takibinin artmasının olumlu etkilerinden biri de, ortaya çıkan konuların toplumda geniş bir kesim tarafından tartışılması gerçeğidir. Bu, medyanın ve sanat ortamının zenginleşmesine izin verir. Olumsuz etkilere gelince, Kamal, televizyon kanallarının çalışmalarının sadece Ramazan ayında mevsimlik bir çalışmaya dönüştüğüne inanmaktadır, bunun da Yemenli izleyicinin ilgi alanlarını yabancı kanallarda aramasına neden olduğunu söyler (Kamal Haydarah, 07.05.2021).

Bu konuda Tawfik Alsharabi'nin farklı bir görüşü vardır. Çünkü Ramazan ayında belirli bir kanalda programların veya dizilerin fazla izlenmesinin olumlu etkisinin tüccarların 
ürünlerini tanıtma yoluyla daha fazla kazanmasıdır. Bu durum Ramazan ayında reklam gösterme karşılığında büyük paralar kazanan kanalların yararına olmaktadır. Olumsuz etkiye gelince, Tawfiq, Ramazan dişında bu kanallarda dizi ve program üretiminin eksikliğinin izleyiciyi alternatif yabancı kanallara yönelten neden olarak görür ve bu görüş Kamal'ın görüşüne benzerdir (Tawfik Alsharabi, 10.05.2021).

Taleb Al-Maamari'nin ise farklı bir görüşü vardır. Taleb Al-Maamari Ramazan ayında izlenme sayısının artmasının olumlu etkilerinden birinin yerel komedi programlarının ve dizilerinin izleyiciyi memnun etmesi ve yüzüne gülümseme getirmesi olduğunu düşünmektedir. Taleb'e göre bu, yerel üretimi teşvik etmekte ve Yemenli izleyicinin, Yemen kimliğini yok etmeye, insanların gelenek ve göreneklerini değiştirmeye ve Yemen toplumu tarafindan reddedilen etik olmayan davranışları sağlamlaştırmaya çalışabilecek yabancı kanalların çoğunu geri çevirmesine neden olmaktadır. Taleb, olumsuz etkilere gelince, izleyici kazanmak için diğer Yemenli partilere yönelik düşmanca programlar yayınlayan bazı siyasi partilere bağlı kanalların olduğunu söylemiştir (Taleb Al-Maamarı, 11.05.2021).

Çoğu Yemen devlet veya özel kanalı, belirli çıkarlara hizmet eden bir siyasi gündeme sahip olarak sınıflandırılır. AlSaeedah tek ticari kanal olarak kabul edilmekte ve çoğu reklam bu kanal üzerinden gösterilmektedir. AlSaeedah, 2015 savaşından önce Yemen'de en çok izlenen ve en popüler olan kanaldır ancak içerik üretiminin zayıflı̆̆ı ve reklam gelirlerinin eksikliğinden dolayı Yemen Shabab kanalı lehine ikinci sıraya gerilmiştir.

Saber Al-Jabri, Ramazan ayında yerel kanalların izlenme sayısının artmasının Yemen görsel medyasının avantajlarından biri olduğunu düşünmektedir. Bu, büyük kitleler tarafından takip edilen içeriğe ulaşmak için kanallar arasındaki rekabeti ve dolayısıyla kanalların bir dereceye kadar kalite standartlarına bağımlılığını artırır. Saber'e göre olumsuz etkiye gelince, diğerlerinin bahsettiklerinden farklı değildir, yani Yemenli TV kanalları Ramazan ayını yerel üretim sezonu olarak görürken yılın geri kalan aylarında yurt dışından ithal edilen konserve malzemelere (içeriklere) geri döner (Saber Al-Jabri, 05.05.2021).

Yukarıdakilerin hepsinden açıkça görülüyor ki, Yemen kanallarındaki üretim eğrisinin Ramazan dışındaki güçlü düşüşü, izleyicinin, çalışmalarının temeli olarak yerel ortamı benimseyen fikirlerle bu kanalların meydan okuma ve yaratıcılığı sürdürme becerisine olan güvenini kaybetmesine neden olmaktadır. İçerik üretimini ve izlenme sayısını artırmak, şüphesiz kanal ve izleyici için olumlu bir şeydir. Üretim eksikliği ise; kanallar, programlar ve diziler için reklamverenlerin ve sponsorların olmaması anlamına gelir ve bu kanal için bir 
kayıptır. Ayrıca üretim eksikliği; izleyicilerin olmaması ve dolayısıyla halkın Ramazan ayı dışında yerel kanalların içeriklerinden entelektüel, kültürel ve sosyal olarak yararlanamamaları anlamına gelmektedir.

\section{DEĞERLENDİRME VE SONUÇ}

Çalışmada YouTube'da Yemen televizyonlarında sunulan pek çok dizi ve programın olduğu, ancak bu kanalların çoğu yapımlarının çok kaliteli olmadığı ve bu nedenle çok fazla izlenmedikleri görülmüştür. Örneğin dizilerini ve programlarını üretmek için yüz binlerce dolar harcamış olan Yemen Shabab kanalı en çok izlenen kanal olmuştur. Kanal yönetim kurulu başkanı tarafından yapılan açıklamaya göre, "Al-Jahmaliyah Geceleri” dizisi için yapılan harcamalar, bu yıl Yemen dizileri arasında en yüksek bütçe olan 400.000 doları aşmıştır ve çekilmesi bir yıl sürmüştür. Dolayısıyle dizi, YouTube'daki diğer Yemen dizileri arasında en yüksek görüntülenmeyi almıştır. Ayrıca AlSaeedah kanalının yapımını ve gösterimini yaptığı "Güneşin Arkası" isimli dizi de izlenme sayısı bakımından ikinci dizi olmuştur. Çünkü dizideki aktörlerin çoğu en önde gelen Yemenli drama yıldızları arasında yer almıştır. Şüphesiz ünlü oldukları için maaşları da yüksek olmuştur.

$\mathrm{Bu}$ çalışmada YouTube'daki görüntülenmeler ile evde TV ekranlarındaki görüntülemelerin boyutunu gerçekten yansıtıp yansıtmadığıdır. Bu sorunun cevabı en çok izlenen "Al-Jahmaliyah Geceleri, Güneşin Arkası ve Cappuccino" gibi dizilerini, Yemen sokağının ve sosyal medyanın sürekli konuşması ve bu nedenle YouTube'daki yüksek görüntülenmelerin normal olduğudur. Bunun yanında, Ramazan boyunca, Al Hawyah kanalındaki "Halk Otobüsü-3" programı ve Suhail kanalındaki "Gaga-5" programı da sosyal medyada çok konuşulmuştur ve izlenme oranı açısından birinci ve ikinci sırada yer almıştır. Oysa web sitelerindeki veya sosyal medyadaki gazeteciler, eleştirmenler, aktivistler ve sıradan insanlar tarafından hiç bahsedilmeyen diziler, programlar ve hatta kanallar bulunmaktadır ve bunlar Yemen sokağında herhangi bir yankı uyandırmamıştır. Bu yüzden en çok izlenen on kanal, dizi veya program listesinde görünmemiştir. YouTube görüntülenmeleri, evlerdeki görüntülenmeyi yansıtmak zorunda değildir, ancak bu sonuçlar göz önüne alındığında sayıların büyük bir yansıması olması gerektiği söylenebilir. En önemlisi, bu çalışma ve geçen yılki araştırmaya göre Ramazan ayı görüntülenmeleri birçok kez Ramazan dışındaki aylardaki görüntülenmeleri aşarak \%500'e ulaşmaktadır. Ramazan ayında içerik üretiminin azlığ veya zayıflığı nedeniyle dört devlet kanalı bu süreçte yer alamamıştır. 
Son olarak araştırmada Yemen uydu kanallarının Ramazan ayı dışında da dizi ve program üretiminde artışlar yaşamasının mümkün olup olmadığına dair bir çıkarsama yapılmıştır. Bunun cevabı izleyicinin televizyon izleme oranlarından çıkarsanabilir. Yemen'de izleyiciler Ramazan dışında televizyon izlemediği sürece, televizyon kanalları da büyük işler üretmeye cesaret edemeyecek, sponsorluk ve reklam alamayacak ve bu nedenle reklamveren veya sponsorlar da izleyicinin izlemediği bir dizi veya programı desteklemeyecektir. 


\section{KAYNAKÇA}

Alexa. (2018). The Top 500 Sites on the Web. Retrieved 05 26, 2021, from Alexa: https://www.alexa.com/topsites

Al-Mutawakil, M. A. (1983). Yemen basınının doğuşu ve gelişimi. Yayımlanmamış doktora tezi, Kahire Üniversitesi, Kahire.

Alnadheef, S. (2020). Youtube'da Ramazan ayında en çok izlenen Yemen televizyon kanallart. 04 25, 2021 tarihinde Yeniyemen: https://yeniyemen.net/p-66484 adresinden alınmıştır.

Çalapkulu, Ç. ve Şimşek, R. (2018). Sosyal Medyanın Reklam Aracı Olarak Kullanılmasında YouTube: Sakarya Üniversitesi İletişim Fakültesinde Bir Araştırma. Uluslararası Sosyal Bilimler Dergisi, 2018, Cilt 1, Say1 2, 269-278.

Çiçek, M. (2018). YouTuber videoları: Kim, Nerede, Ne zaman, Nasıl, Neden İzler. Avrasya Sosyal ve Ekonomi Araştırmaları Dergisi (ASEAD), 2018, Cilt 5, Sayı 7, 163-170. ISSN:2148-9963.

El-Ağberi, S. (2014). Yemen medyasına giriş. Sanaa: Üniversite Kitabevi.

El-Haşimi, R. (2018). Elektronik terörizm (1. bs). Amman: Daru Amjad Yayıncılık Dağıtım.

Ez-Zelb, A. (2003). Yemen'de televizyon. Yemen ansiklopedisi (C.1.). Sanaa: El- Afif Kültür Kurumu.

Fanack. (2017). Media overview in Yemen. 05 19, 2021 tarihinde Fanack: https://fanack.com/ar/yemen/society-media-culture/media/ adresinden alınmıştır.

Gönenli, G. ve P. Hürmeriç. (2012). Sosyal Medya bir Alan Çalışması Olarak Facebook Kullanımı. T. kara ve E. Özgen (Ed.). Sosyal Medya Akademi içinde (1. bs). İstanbul: Beta Basım Yayım, 213-242.

Güven, S. (2001). Toplumbiliminde araştırma yöntemleri (2. bs). Bursa: Ezgi Kitabevi Yayınları.

İman, B ve H. Marzouki. (2009) Web 2.0 Yeni medya ve sosyal ă̆ları. Cezayir: Badji Mokhtar Üniversitesi. 
Nasr, H. M. (2008). Kitle iletişimine giriş. Kuveyt: Al Falah Kütüphanesi.

Nouh, M. (2006). Eğitim araştırmasının ilkeleri. Suudi Arabistan: Tabuk Üniversitesi, ElRashed Kütüphanesi.

Statista. (2018). Youtube: Statistics and facts. Retrieved 05 07, 2021, from Statista: https://www.statista.com/topics/2019/youtube/

Watania. (2020). Tüm Yemen kanallarının frekanslart. 04 29, 2021 tarihinde Watania: https://www.watania.net/news/154577 adresinden alınmıştır.

Yemen TV. (2019). Yemen'de televizyon. 05 13, 2021 tarihinde YemenTV: http://yementv.net/index.php?mod=contents\&do=view\&cid=35\&id=152 adresinden alınmıştır.

Yıldırım, A ve H. Şimşek. (2011). Sosyal bilimlerde nitel araştırma yöntemleri (8. bs). Ankara: Seçkin Yayıncılık.

Yıldırım, E. (2018). Ne Danla Bilic Ne de Enes Batur! Prenses Elif 2,5 Milyar Defa İzlendi. 05 03, 2021 tarihinde Youtubeturkiye: https://www.youtubeturkiye.net/ne-damla-bilicne-de-enes-batur-prenses-elif-25-milyar-defa-izlendi/ adresinden alınmıştır.

Yicon. (2019). Internet'te Yemen. Sanaa: DMYemenicon.

YouTube (2018). YouTube Hakkında. 05 08, 2021 tarihinde Youtube: https://www.youtube.com/intl/tr/yt/about/ 